\title{
Exploring Student's Readiness and Behavioural Towards Virtual Learning via Microsoft Teams
}

\author{
Amani Nawi ${ }^{*}$ (D), Umi Hamidaton² iD \\ 1Fakulti Pengajian Bahasa Utama, Universiti Sains Islam Malaysia (USIM), 71800, Nilai, Negeri Sembilan, \\ Malaysia. \\ Email: amani@usim.edu.my \\ ${ }^{2}$ Fakulti Ekonomi \& Muamalat, Universiti Sains Islam Malaysia (USIM), 71800, Nilai, Negeri Sembilan, \\ Malaysia. \\ Email: umihamidaton@usim.edu.my
}

\author{
CORRESPONDING \\ AUTHOR (*): \\ Amani Nawi \\ (amani@usim.edu.my) \\ KEYWORDS: \\ Student's readiness \\ Virtual learning \\ Microsoft Teams

\section{CITATION:} \\ Amani Nawi \& Umi Hamidaton. (2022). \\ Exploring Student's Readiness and \\ Behavioural Towards Virtual Learning via \\ Microsoft Teams. Malaysian Journal of \\ Social Sciences and Humanities (MJSSH), \\ 7(2), e001273. \\ https://doi.org/10.47405/mjssh.v7i2.1273
}

\begin{abstract}
Implementation of online learning in the era of COVID-19 pandemic has become a global issue and had a major impact on higher education. The Movement Control Order (MCO) carried out in Malaysia has affects many higher institutions. All students especially undergraduate students who just starting their new semester has forced to stay at home while learning activities continue virtually using a various platform such as Microsoft Teams. Microsoft Teams considered as an excellent collaboration platform complete with useful features to enhance virtual learning environment as well for educational purposes. The main objective of this research is to explore the level of student's readiness and behaviour towards virtual learning using Microsoft Teams. The study uses a cross-sectional survey consist of 312 undergraduate students at Universiti Sains Islam Malaysia (USIM) from various program of study. Data were collected by using questionnaires to gain information about the students' perception on their readiness and behaviour towards virtual learning via Microsoft Teams. By using descriptive statistical analysis, this study found that readiness among undergraduate students is at a medium high level, while student behaviour considered at a highlevel despite Microsoft Teams platform is regarded as something new for the students. The finding revealed that students easily operate the platform without further training.
\end{abstract}

Contribution/Originality: This study contributes to the existing literature that mainly discuss on virtual learning practice by students during the pandemic Covid-19 which offers a few implications during the learning process mainly focusing on online platform such as Microsoft Teams. This study can serve as one of pioneers that offer information on student's e-learning acceptance and behavior that will benefit other local institutions. 


\section{Introduction}

Since the COVID-19 epidemic hit the world, all higher education institutions across the country have been enforced to carried out learning and teaching activities through online platform, so that students can continue the study process as usual to avoid delays in studies as the current semester is still in progress. It is estimated that over 421 million students have been affected because of the closure of educational institutions involving 39 countries while 22 countries have decided to close part of their local education operations (Tam \& El Azhar, 2020). In this regard, Malaysia is no exception in implementing online teaching and learning sessions due to the spread of the COVID-19 pandemic.

When the government announced the implementation of the first phase of the Movement Control Order (MCO) starting March 16, 2020 and continuing until present, most public, and private institutions of higher learning have taken initiatives and strategic measures to implement comprehensive online teaching and learning sessions. Therefore, all courses offered by the university and faculty have been held virtually to replace the conventional method of face to face.

In brief, online teaching and learning is an educational system that exploits technology such as internet, satellite power and interactive network systems in delivering information such as lecture materials, assessments, projects as well as assignments and presentations to students (Atousa, Zahra \& Mohammad, 2016). These processes are also identified as online learning systems or virtual learning systems (Bentley et al., 2012).

Online learning systems are a method that allows educators and students to conduct teaching and learning sessions anywhere and anytime even outside of lecture time and hall (Verawadina et al., 2020). According to Golzari et al. (2010), the use of online learning platforms is an appropriate strategy to improve the quality in the teaching and learning process especially in today's 4.0 industry era.

There are several online platforms that can be used for this purpose such as Google Classroom, Zoom, Microsoft Teams, WebEx, as well as other social media platforms such as WhatsApp, Telegram and YouTube (Chung et al., 2020). As each university has its own learning system (LMS), but the pandemic situation that hit today demands the use of the latest applications and technologies that are more comprehensive to succeed in teaching and learning activities synchronously or asynchronous.

In line with the recommendation by the Ministry of Higher Education Malaysia to change the method of face-to-face to virtual learning during MCO, many universities are trying to find the best virtual teaching platform that suit both educators and student's accordance with the pandemic situation beside their current LMS system. One of the preeminent virtual learning applications is Microsoft Teams. Microsoft Teams is an application or interaction platform introduced by the Microsoft company. The app is integrated directly into Microsoft Office 360 allowing a subscribing person or institution to connect, communicate, collaborate, and perform all activities easily and quickly. Microsoft Teams not only allows the community to collaborate live and share files from one place, but lecturers and students can meet virtually as in a lecture hall (Buchal \& Songsore, 2019; Henderson et al., 2020). Besides, it is also can easily be downloaded through desktop and mobile applications, and its features are exploited by people everywhere (Ahmad Ridho, 
2020). Tsai (2018) discovered that by the end of $2020,41 \%$ of various organizations are expected to use Microsoft Teams globally.

Hence, the current study is designed to assess the students' readiness of students in Universiti Sains Islam Malaysia (USIM) from different majors to engage in virtual learning using Microsoft Teams. Considering the above explanations, the researcher is interested to conduct this study to explore whether the skills and attitude of students are enough to make possible implementation of virtual learning via Microsoft Teams.

\section{Literature Review}

Several studies were conducted recently related to implementation of online learning among students as an important initiative to improve education system due to impact of pandemic Covid-19. Through online learning students as participants can access their lesson, communicate in with lecturers and able to collaborate with others wholly via online. In fact, developing country as Thailand has supported the use of technologies to provide online learning by using technologies that has made improvement to strengthen learning infrastructure and university network capacity (Ngampornchai \& Adam, 2016; Olusegun et al., 2006).

In 2020, emergence of Coronavirus pandemic has not only given impact on human life but also involve major shift in global educational system. With Pandemic Covid-19 made others realize the importance of online learning. With the principles of social distancing, all face-to-face class were suspended due to ongoing pandemics. Students especially in higher education institutions are among the most affected by the widespread of COVID19 as the learning sessions which were initially conducted face-to-face are converted into online learning sessions in ensuring the continuity of the on-going education process (Chung et al., 2020). Many universities both locally and abroad are getting to engage into online learning sessions as the best alternative to ensure the students can go through their studies as usual despite of the current scenario and circumstances. University of Cambridge, for an instance is the first university in the United Kingdom to be fully involved in online teaching and learning for 2020/2021 academic session to curb the spread of COVID-19 among the staff and students at the university (Europe News, 2020).

The increase acceptance among students on online teaching and learning platforms has been recorded by Radford and Weko (2011) where the enrolment to courses offered online increased from $8 \%$ in 2000 to $20 \%$ in 2008 . The recorded increase thus indicated that the students are ready to the new norm of the teaching and learning session using existing platforms. A study conducted by the Arthur M. Blank Centre for Entrepreneurship, Babson College on 2800 higher education centres showed similar findings where the enrolment to online courses increased drastically in 2013 from 411 to 701 million students (Allen \& Seamnan, 2014; Van Rooji \& Zirkle, 2017). This signified that the student in general is accepting online teaching and learning process with the use of several platforms such as Google Classroom, Zoom, Microsoft Teams, Webex, etc.

Apart from that, Malaysia is involved in the transition phase of online teaching and learning process as the Ministry of Higher Education (MoHE) has announced that all universities in the nation both public and private to engage in online teaching and learning until the end of 2020 (Malaysian Ministry of Higher Education, 2020) parallel to the Movement Control Order implemented by the government to curb the spread of COVID19. 
There are recent studies conducted focusing on the readiness and acceptance among students of higher education institutions on online teaching and learning sessions. Among which are the studies conducted by Atkinson and Blenakenship (2009), Chung et al. (2020), and Hung et al. (2010). Hung et al. (2010) in their study examined the readiness level of the students through five main dimensions which were self-directed learning, student control, computer and internet effectiveness, self-efficiency in online communication, and motivation to learn. This study, on the other hand, will be focusing on attitude, knowledge level, and motivation of the students as key indicators to measure their acceptance on the use of online teaching and learning platforms specifically Microsoft Teams.

Based on the following the discussion, four research questions guide this paper:

i. What is the level of students' readiness for virtual learning in terms of their skill in using Microsoft Teams?

ii. Are there any significant differences in students' readiness for virtual learning using Microsoft Teams based on gender, program of study and year of study?

iii. What is the students' behaviour towards the use of Microsoft Teams as main platform in virtual learning?

iv. Are there any significant differences in students' behaviour towards the use of Microsoft Teams as main platform in virtual learning based on their gender, program of study and year of study?

\section{Research Method}

\subsection{Research Design and Respondents}

This study utilized a cross -sectional research method that allows researchers relied on a structured questionnaire and used measures from previous research, where available. The method used can help researchers obtain more accurate data collection, no element of bias to ensure that only quality data can be collected (Creswell, 2008; Sekaran \& Bougie, 2010). In addition, the method of data collection through the distribution of questionnaires as a research instrument is appropriate because this method is easier to get cooperation from respondents as a research sample and even it is the most appropriate method if the study is survey (Jones, 1996). In addition, the method of data collection through questionnaires or surveys is suitable to be used to obtain information related to attitudes, perceptions, and views other than background information (Siti Fatimah \& Siti Hasmiza, 2018).

This study was conducted at local higher educational institution in Nilai which is Universiti Sains Islam Malaysia (USIM). The respondents involved all undergraduate students at from various program of study; 1) Faculty of Major Language (FPBU), Faculty Quran Sunnah Studies (FPQS), Faculty of Syariah and Law (FSU), Faculty of Medicine and Health Sciences (FPSK), Faculty of Leadership and Management (FKP), Faculty of Science and Technology (FST) and Faculty of Dentistry (FPg). Researchers use a convenience sampling which this method is considered the most suitable for use in survey studies. Among the advantages of the simple sampling technique is that the researcher can use the closest study subject to participate in the study. Participation from the respondents was voluntary and anonymous. The demographic profile of the respondents is indicated in Table 1. 
Table 1: Respondents' demographic background

\begin{tabular}{llll}
\hline Background & Variable & N & \% \\
\hline Gender & Male & 71 & 22.8 \\
& Female & 241 & 77.2 \\
\hline Program of Study & FPBU & 24 & 7.7 \\
& FPQS & 31 & 9.9 \\
& FSU & 152 & 48.7 \\
& FPSK & 27 & 8.7 \\
& FKP & 27 & 8.7 \\
& FST & 46 & 14.7 \\
& FPg & 5 & 1.6 \\
\hline Year of Study & Year 1 & 123 & 39.4 \\
& Year 2 & 114 & 36.5 \\
& Year 3 & 69 & 22.1 \\
& Year 4 & 6 & 1.9 \\
\hline
\end{tabular}

Data were collected in the end of semester 2 2019/2020 during the first phase of the Movement Control Order (MCO) implementation due to COVID-19, where the learning activities begin virtually by using the MS Teams as one of major online platform widely in online learning in USIM. A total of 312 undergraduate students were participated in answering the questionnaire and were selected as the study sample.

\subsection{Instrument}

At the initial stage of this research, the survey questionnaire was develop based on virtual or online learning literature. The research instrument used adapted from Noraffandy and Ling (2011). Subsequently, improvements in the content of the questionnaire were shepherded for the purpose and context of the current study. The questionnaires consist of three sections. Section A collects personal information of respondents. Section B of the Questionnaire gauges the student's readiness towards virtual learning via Microsoft Teams (8 items), while the section $\mathrm{C}$ is to assess student's behavioural toward Microsoft Teams application as a virtual learning platform ( 9 items). Total items are 17. Respondents are required to answer the questions based on five-point Likert scale format; (5) Strongly Agree, (4) Agree, (3) Neutral, (2) Disagree, (1) Strongly Disagree. All the responses were collected online through the Google Forms as electronic survey tool.

\subsection{Validity and Reliability}

The researchers have used appropriate statistical tools and techniques to ensure the validation and analysis of the collected data. The reliability of data was processed by using Statistical Package for Social Sciences (SPSS) version 2.6 Software. This study used Cronbach's alpha as a measure of reliability, which is a commonly applied measure in Likert scale survey. Although the instrument was validated by previous researcher, it is essential to test its reliability within the context of the current study. Data collected from Google Form was screened, cleaned, and transferred to SPSS for analysis purpose. Cronbach Alpha's reliability coefficient for all variables in the instrument are above 0.70. The reliability value of Cronbach's alpha between 0.41 and 0.70 qualifies for moderate reliability of the scale measured, while greater value than 0.70 shows high internal consistency (Sekaran \& Bougie, 2016). Thus, the reliability result for this study shows a good internal consistency (Hair et al., 2014). 
Before the questionnaire distributed to the respondents, back to back translation technique was used to translate the questionnaire into Malay and English language in order to enhance validity and reliability of research outcomes (Creswell, 2008; Sekaran \& Bougie, 2016).

\subsection{Data Analysis}

Table 2 interpret how the five-point Likert scale is divided into mean level scales. The fivepoint Likert scale ranged from 1 (strongly disagree) to 5 (strongly agree). The researchers use the mean difference proposed by Nunally (1978) which the mean divided into four categories namely low, medium low, medium high and high.

Table 2: Mean Interpretation

\begin{tabular}{ll}
\hline Mean Value & Interpretation \\
\hline $1.01-2.00$ & Low \\
$2.01-3.00$ & Medium Low \\
$3.01-4.00$ & Medium High \\
$4.01-5.00$ & High \\
\hline
\end{tabular}

\section{Finding and Discussion}

\subsection{Student's Readiness for Virtual Learning via Microsoft Teams}

The first research question in this study was what is the level of students' readiness for virtual learning in terms of their skill in using Microsoft Teams?

Overall findings indicated that students were ready for the virtual learning in terms of their skill and knowledge in using Microsoft Teams as main platform as the overall mean score of the items is between moderate and high. According to Table 3, among the eight items of readiness for virtual learning, students rated highest on their awareness of the importance of Microsoft Teams as main platform (item 6) to conduct virtual learning with a mean score of $\mathrm{M}=4.46, \mathrm{SD}=0.640$.

Table 3: Mean for Readiness Items

\begin{tabular}{|c|c|c|c|}
\hline No & Items & Mean & Std Deviation \\
\hline 01 & I have skill on using Microsoft Teams & 3.90 & 0.647 \\
\hline Q2 & $\begin{array}{l}\text { I always face an obstacle while using Microsoft } \\
\text { Teams due to lack of knowledge about it. }\end{array}$ & 2.38 & 0.937 \\
\hline Q3 & $\begin{array}{l}\text { I am aware that USIM is using Microsoft Teams as } \\
\text { virtual teaching main platform. }\end{array}$ & 2.39 & 0.963 \\
\hline Q4 & I realize that Microsoft Teams has many advantages. & 4.31 & 0.714 \\
\hline Q5 & $\begin{array}{l}\text { I know that I will be left behind if I do not use } \\
\text { Microsoft Teams. }\end{array}$ & 4.13 & 0.869 \\
\hline Q6 & $\begin{array}{l}\text { I am aware that I need to use Microsoft Teams for } \\
\text { virtual learning during MCO. }\end{array}$ & 4.46 & 0.640 \\
\hline Q7 & $\begin{array}{l}\text { *I don't have ability to use Microsoft Teams } \\
\text { effectively. }\end{array}$ & 2.34 & 0.969 \\
\hline Q8 & $\begin{array}{l}\text { I know how to use all features available in Microsoft } \\
\text { Teams for learning purposes. }\end{array}$ & 3.76 & 0.864 \\
\hline
\end{tabular}

* Negative item 
In the other side, lowest mean score rated by the students is item 7 which $\mathrm{M}=2.34, \mathrm{SD}=$ 0.969. It's indicated that majority of the students are ready to participate in virtual learning in terms of their ability and confident in their skill to operate and utilize the Microsoft Teams software. The rest of the results on students' readiness for virtual learning via Microsoft Teams are summarised in Table 3.

\subsection{Difference Between Student Profile and Readiness for Virtual Learning}

The second research question in this study was to examine if gender, program of study and year of study of the students make any difference in their readiness for online learning. To answer this question, the overall online learning readiness was further tested to examine whether there was any significant relationship between readiness and respondents' demographics variables.

According to result of Table 4, it shows that gender had similar level of mean score even though that the means score of females had slightly higher than males. It was indicated that both male and female did not exhibit any significant difference in their overall readiness for virtual learning.

Table 4: Differences between Student Profile and Readiness

\begin{tabular}{lllll}
\hline Profile & & Mean & N & Std Deviation \\
\hline Gender & Male & 3.39 & 71 & 0.379 \\
& Female & 3.48 & 241 & 0.352 \\
Program of & FPBU & 3.55 & 24 & 0.421 \\
Study & & & \\
& FPQS & 3.60 & 31 & 0.412 \\
& FSU & 3.45 & 152 & 0.357 \\
& FPSK & 3.36 & 27 & 0.271 \\
& FKP & 3.54 & 27 & 0.341 \\
& FST & 3.36 & 46 & 0.299 \\
Year of Study & FPg & 3.52 & 5 & 0.547 \\
& Year 1 & 3.50 & 123 & 0.357 \\
& Year 2 & 3.39 & 114 & 0.367 \\
& Year 3 & 3.50 & 69 & 0.339 \\
& Year 4 & 3.35 & 6 & 0.398 \\
\hline
\end{tabular}

As for the programs of study, the finding show that students from two faculties which are Faculty of Medicine and Health Sciences (FPSK) and Faculty of Science and Technology (FST) were not too confident in their readiness for virtual learning compared to other programs of study with each of their score mean is at moderate level. Despite these two programs considered science study, students of Faculty of Dentistry (FPg) scored higher with very small respondents (mean:3.52, $\mathrm{n}=5$ ). The different of their perceptions towards readiness for virtual learning might not come from technical operational obstacles of the platform used. Instead, it might be due to the nature of the subject taken in the semester which required clinical and laboratory studies. This finding supported by Mohammad $\mathrm{H}$ Rajab, Abdalla and Khaled Alkattan (2020) who reported challenges in online learning during COVID-19 pandemic among medical students do not just included issues related to the to use of technology tools, but also unsuitable learning material and absent of clinicals tools. Otherwise, students from art program such as FPQS (mean:3.60, $\mathrm{SD}=0.412)$, FPBU (mean:3.55, SD=0.421), FKP (mean:3.54, SD=0.341) and FSU 
(mean:3.45, SD=0.357) shows high score towards their skill and readiness in pursuing their learning virtually.

As for the year of study, the finding show that majority of the students from all year of the study express their positive perceptions towards virtual learning environment. The score means from fourth year students are slightly lower than other students. The reason may lie in students' activity and involvement in field study and final year project. Some of the students need to do their internship where they don't have any class to attend online.

\subsection{Student's Behaviour towards MS Teams application as a virtual learning platform}

Table 5 shows the result of student's behaviour towards MS Team which related reflect the third research question on 'What are the student's behaviour towards the use of MS Teams as main platform of learning?' Overall finding indicates that their behaviour to apply this online platform is between medium (low) and high from mean 2.39 until 4.02. Based on the results finding, among nine items to measure their behaviour on virtual learning platform, students highest rated on their behaviour of readiness to use Ms Team during virtual lesson conduct with a mean score of $\mathrm{M}=4.02, \mathrm{SD}=0.885$. The students liked the facts that online learning can be used at anytime and anywhere.

Table 5: Mean for Behavioural Items

\begin{tabular}{llll}
\hline No & Items & Mean & $\begin{array}{l}\text { Std } \\
\text { Deviation }\end{array}$ \\
\hline Q9 & I am ready to use Microsoft Teams at any time. & 4.02 & 0.885 \\
Q10 & I am always learning how to use Microsoft Teams. & 3.99 & 0.767 \\
Q11 & $\begin{array}{l}\text { I am prepared to face challenges in the use of } \\
\text { Microsoft Teams. }\end{array}$ & 3.89 & 0.823 \\
Q12 & $\begin{array}{l}\text { I rarely encourage friends to use Microsoft Teams. } \\
\text { Q13 }\end{array}$ & $\begin{array}{l}\text { I think Microsoft Teams is my preferred virtual class } \\
\text { application. }\end{array}$ & 3.80 \\
Q14 & $\begin{array}{l}\text { I use Microsoft Teams as main platform for virtual } \\
\text { class in all subjects. }\end{array}$ & 3.99 & 0.979 \\
Q15 & $\begin{array}{l}\text { I use Microsoft Teams to communicate with } \\
\text { classmates. }\end{array}$ & 3.53 & 0.938 \\
Q16 & $\begin{array}{l}\text { I use Microsoft Teams to communicate with } \\
\text { lecturers. }\end{array}$ & 3.60 & 1.116 \\
Q17 & $\begin{array}{l}\text { I always interact actively while using Microsoft } \\
\text { Teams for virtual class. }\end{array}$ & 3.35 & 0.941 \\
\hline
\end{tabular}

This finding also supported by research have been done by Teo et al. (2011), found that the acceptance of students towards virtual learning was above average and students have positive attitudes and behaviour to adopt technology skills. Besides, this positive outcome as view of online platform is convenient and efficient for virtual learning as a result shows by items $\mathrm{Q} 13$ with a mean score of $\mathrm{M}=3.80, \mathrm{SD}=0.933$. On the other hand, lowest mean score rated by the students is item $\mathrm{Q} 12$ which $\mathrm{M}=2.39, \mathrm{SD}=0.979$. It indicates that, students rarely encourage others to use MS Teams. It may be due to difficulties of communication practices during the virtual learning (Ngampornchai \& Adams, 2016). In fact, numerous challenges were discussed with regards to promote positive behaviour and attitudes towards online learning especially among developing countries (Ngampornchai \& Adams, 2016). 


\subsection{Difference Between Student Profile and Behaviour towards Microsoft Teams application as a virtual learning platform}

Table 6 indicate the result to identify are there any difference on student's behaviour towards Microsoft Teams according to gender, program and years of study? As stated, according to gender there are similar level of mean score between male and female students' behaviour towards the online platform used in virtual learning. It indicates both female and female did not exhibit any significant difference in their overall behaviour and attitudes towards Microsoft Teams as virtual online learning platform.

Based on program of study, the finding shows Faculty of Dentistry (FPg) achieved high level of mean score compared to others $(M=4.08$, SD 0.540$)$ as they have very small respondents $(n=5)$. On the other hand, overall, there are no significant difference in terms of behaviour among students from other faculty in USIM towards the use of Microsoft Teams as virtual learning platform.

Table 6: Student Profile and Behavioural Factors

\begin{tabular}{lllll}
\hline Profile & & Mean & N & Std Deviation \\
\hline Gender & Male & 3.46 & 71 & 0.636 \\
& Female & 3.66 & 241 & 0.512 \\
Program of & FPBU & 3.64 & 24 & 0.561 \\
Study & & & \\
& FPQS & 3.79 & 31 & 0.537 \\
& FSU & 3.62 & 152 & 0.490 \\
& FPSK & 3.72 & 27 & 0.420 \\
& FKP & 3.73 & 27 & 0.553 \\
& FST & 3.31 & 46 & 0.676 \\
Year of Study & FPg & 4.08 & 5 & 0.540 \\
& Year 1 & 3.70 & 123 & 0.458 \\
& Year 2 & 3.49 & 114 & 0.572 \\
& Year 3 & 3.66 & 69 & 0.591 \\
& Year 4 & 3.68 & 6 & 0.925 \\
\hline
\end{tabular}

Covid-19 pandemic made students realize the need and important of virtual learning through their positive respond and feedback to use Microsoft Teams as one of e-learning platform. Microsoft Teams as an innovative online learning platform provides unique features to enhance better interaction among users as well else promote friendly learning environment in virtual learning (Rojabi, 2020).

Besides, according to year of study, the finding shows that majority from all years of study (Year 1 until Year 4) shows moderate level of behaviour as score mean range between 3.49 (Year 2) - 3.70 (Year 1). As a result, there are no significance difference in terms of year of study towards behaviour of student upon Microsoft Teams application as a virtual learning platform. It may be due as an action that their properly understood Microsoft Team as a main learning method used in USIM.

Virtual learning is one of effective way to provide students with engaged learning process, improve learning skills as well as develop high level of critical thinking skills. Microsoft Teams become an effective online learning platform because it acts as a cloud app digital hub that connects chat, meeting file and apps together in a single Learning Management System (LMS) (Rojabi, 2020). According to Tsai (2018) Microsoft Teams will exist in 
advance over the next two years then, by the end of $2020,41 \%$ of organizations expect to use Microsoft Teams globally.

\section{Conclusion}

The concept and practise of education has change dramatically over last few years, with many indicators and reasoned being raised due to current situation especially due to impact of pandemic Covid-19. The pandemics contributed to the faster transition towards the new stage of Education 4.0 that impose online or virtual education.

Based on the finding discussed above, the participants seemed to indicate their acceptance, readiness and positive behaviour towards the use of Microsoft Teams as virtual learning platform where they were being exposed obliquely during pandemic. Positive perception and student's confidence in their skills will describe their readiness to be in online learning environment. Virtual classes using Microsoft Teams able to supports the students learning environment optimally as majority of this research respondents had a favourable opinions and feedback outcome from their own experience in virtual learning by using Microsoft Teams platform. Furthermore, online learning facilitates interaction between students as well as between students and teachers.

Besides, the study contributes to the present body of knowledge on virtual learning practice using Microsoft Teams as main learning platform by focusing on students' perception, readiness and behaviour to adopt virtual online practice in education. According to Allen and Seamen (2017) about six million students enrolled in at least one higher education online course in 2015 compared to 2002 only 1.6 million. It indicates that the use of technology and digital platform can help people live, one of which in the sphere of education. In fact, previous research by Peterson et al. (2018), Martin and Tapp (2019) shows that synchronous learning has improved student interactions and collaboration hence the students can engage, interact as well as collaborate actively.

In sum, this research has given a view of student's perception of online learning practice that able to provides directions for the lecturer, faculty management and to the university to apply best practice of virtual learning in the future. Suggestion for future study to explore the comparison between online learning platform in delivering the teaching and its effectiveness towards virtual learning implementation.

\section{Acknowledgement}

The authors very much appreciate the respondents of this study who have provided their cooperation and views in pursuing the objectives of this study. The opinions and assumptions expressed by the authors herein do not necessarily or reflect of the position of institution where the authors belong to.

\section{Funding}

This study received no funding.

\section{Conflict of Interests}

The authors declare no conflict of interest in this study. 


\section{References}

Ahmad Ridho Rojab. (2020). Exploring EFL Students' Perception of Online Learning via Microsoft Teams: University Level in Indonesia. English Language Teaching Educational Journal, 3(2), 163-173.

Allen, I. E., \& Seaman, J. (2014). Grade change: Tracking online education in the United States. Babson Park, MA: Babson Survey Research Group.

Allen, I. E., \& Seaman, J. (2017). Distance Education Enrolment Report 2017. Digital Learning Compass.

Atkinson, J., \& Blankenship, R. (2009). Online learning readiness of undergraduate college students: A comparison between male and female students. The Journal of Learning in Higher Education, 5, 49-56.

Atousa Rasouli, Zahra Rahbania \& Mohammad Attaran. (2016). Students' Readiness for Elearning Application in Higher Education. Malaysian Online Journal of Educational Technology, 4(3), 51-64.

Bentley, Y., Selassie, H., \& Shegunshi, A. (2012). Design and Evaluation of Student-focused eLearning. Electronic Journal of E-Learning, 10(1), 1-12.

Buchal, R., \& Songsore, E. (2019). Using Microsoft Teams To Support Collaborative Knowledge Building in the Context of Sustainability Assessment. Proceedings of the Canadian Engineering Education Association (CEEA), 1-8.

Chung, E., Noor, N. M., \& Vloreen Nity Mathew. (2020). Are You Ready? An Assessment of Online Learning Readiness among University Students. International Journal of Academic Research in Progressive Education and Development, 9(1), 301-317.

Creswell, J. W. (2008). Educational research: Planning, conducting, and evaluating quantitative and qualitative research, ( $3^{\text {rd }}$ ed.). Upper Saddle River, NJ: Pearson Education, Inc.

Europe News. (2020). Retrieved from: https://www.neweurope.eu/article/cambridgeuniversity-movesto-full-year-of-online-learning/

Golzari, Z., Kiamanesh, A., Ghorchian, G. N., \& Ghafari, P. (2010). Development and accreditation of a model for internal evaluation of E-Learning courses. Journal of Higher Education Curriculum Studies, 1(1), 160-185.

Hair, J. F., Black, W. C., Babin, B. J., \& Anderson, R. E. (2014). Multivariate Data Analysis. Pearson Education Limited.

Henderson, D., Woodcock, H., Mehta, J., Khan, N., Shivji, V., Richardson, C., Aya, H., Ziser, S., Pollara, G., \& Burns, A. (2020). Keep Calm and Carry on Learning: Using Microsoft Teams to Deliver a Medical Education Programme during the COVID-19 Pandemic. Future Healthcare Journal, 7(3), 1-4.

Hung, M. L., Chou, C., Chen, C. H., Own. Z. Y. (2010). Learner readiness for online learning: Scale development and student perception. Computers \& Education, 1080-1090.

Jones, K. H., Womble, M. \& Searcy, C. A. (1996). T \& I Education Students. Perceptions of Cources. Journal of Industrial Teacher Education, 34, 82 - 101.

Malaysian Ministry of Higher Education. (2020). Press Release by the Malaysian Ministry of Higher Education, retrieved from https://www.nst.com.my/education/2020/06/599586/overseas-dream-put-hold.

Martin, L., \& Tapp, D. (2019). Teaching with Teams: An introduction to teaching an undergraduate law module using Microsoft Teams. Innovative Practice in Higher Education, 3(3), 58-66.

Mohammad H Rajab, Abdalla M Gazal, \& Khaled Alkattan. (2020). Challenges to Online Medical Education During the COVID-19 Pandemic. Cureus, 12(7), e8966. 
Ngampornchai \& Adams (2016). Students' acceptance and readiness for E-learning in Northeastern Thailand. International Journal of Educational Technology in Higher Education, 13(34), 1-13.

Noraffandy Yahaya \& Ling, N. N. (2011). Kesediaan penggunaan e-learning di kalangan pelajar tahun kedua kursus Sarjana Muda Sains, Komputer Serta Pendidikan, Fakulti Pendidikan, Universiti Teknologi Malaysia - satu tinjauan. Jurnal of Educational Social Science, 1, 121-140.

Olusegun et al. (2006). An exploratory study of the critical factors affecting the acceptability of e-learning in Nigerian universities. Information Management \& Computer Security, 14(5), 496-505.

Peterson, A. T., Beymer, P. N., \& Putnam, R. T. (2018). Synchronous and Asynchronous Discussions: Effects on Cooperation, Belonging, and affect. Online Learning Journal, 22(4), 7-25.

Radford, A. W., \& Weko, T. (2011). Learning at a distance: Undergraduate enrolment in distance education courses and degree programs. Washington: National Center for Education Statistics.

Rojabi, A. R. (2020). Exploring EFL Students' Perception of Online Learning via Microsoft Teams: University Level in Indonesia. English Language Teaching Educational Journal, 3(2), 163-173.

Sekaran, U., \& Bougie, R. (2010). Research methods for business: A skill-building approach (5th ed.). Haddington: John Wiley \& Sons.

Sekaran, U., \& Bougie, R. (2016). Research Methods for Business: A Skill Building Approach. John Wiley \& Sons: New York: USA.

Siti Fatimah Md Azali \& Siti Hasmiza Hassan. (2018). Kajian Penerimaan Pelajar Terhadap Kaedah Massive Open Online Course (MOOC) Sebagai Medium Pembelajaran Di Politeknik Sultan Abdul Halim Mu'adzam Shah, Jitra, Kedah. Journal of Technical and Vocational Education, 1, 73-86.

Tam, G. \& El-Azar, D. (2020). 3 ways the coronavirus pandemic could reshape education. The World Economic Forum COVID Action Platform. Retrieved from https://www.weforum.org/agenda/2020/03/3-ways-coronavirus-is-reshapingeducation-and-what-changes-might-be-here-to-stay/.

Teo, T., Luan, W. S., Thammetar, T., \& Chattiwat, W. (2011). Assessing e-learning acceptance by university students in Thailand. Australasian Journal of Educational Technology, 27(8), 1356-1368.

Tsai, P. (2018). Business Chat Apps in 2018: Top Players and Adoption Plans. The Spiceworks Community. Retrieved from https://community.spiceworks.com/blog/3157business-chat-apps-in-2018-topplayers-andadoption-plans\%0A

Van Rooij, S. W. \& Zirkle, K. (2017). Balancing pedagogy, student readiness and accessibility: A case study in collaborative online course development. Internet and Higher Education, 28, 1- 7.

Verawadina, U., Jalinus, N., Krismadinata, Widya, R. N., \& Simeru, A. (2020). Needs Assessment of ELearning Vocational Education. International Journal of Innovation, Creativity and Change, 11(4), 262- 274. 